\title{
Plate waste and intake of school lunch based on the new Nordic diet and on packed lunches: a randomised controlled trial in 8- to 11-year-old Danish children
}

\author{
Anne V. Thorsen ${ }^{1}$, Anne D. Lassen ${ }^{1}$, Elisabeth W. Andersen ${ }^{2}$, Lene M. Christensen ${ }^{1}$, Anja Biltoft-Jensen ${ }^{1}$, \\ Rikke Andersen ${ }^{1}$, Camilla T. Damsgaard ${ }^{3}$, Kim F. Michaelsen ${ }^{3}$ and Inge Tetens ${ }^{1}$ \\ ${ }^{1}$ Division of Nutrition, National Food Institute, Technical University of Denmark, Soborg, Denmark. \\ ${ }^{2}$ Department of Applied Mathematics and Computer Science, Technical University of Denmark, Soborg, Denmark \\ ${ }^{3}$ Department of Nutrition, Exercise and Sports, Faculty of Science, University of Copenhagen, Copenhagen, Denmark.
}

(Received 24 March 2014 - Final revision received 10 October 2014 - Accepted 15 December 2014)

Journal of Nutritional Science (2015), vol. 4, e20, page 1 of 9

doi:10.1017/jns.2015.3

Abstract

The aim of the present study was to compare total food intake, total and relative edible plate waste and self-reported food likings between school lunch based on the new Nordic diet (NND) and packed lunch from home. In two 3-month periods in a cluster-randomised controlled unblinded cross-over study 3rd- and 4th-grade children ( $n$ 187) from two municipal schools received lunch meals based on NND principles and their usual packed lunch (control). Food intake and plate waste $(n$ 1558) were calculated after weighing lunch plates before and after the meal for five consecutive days and self-reported likings $(n 905)$ assessed by a web-based questionnaire. Average food intake was $6 \%$ higher for the NND period compared with the packed lunch period. The quantity of NND intake varied with the menu $(P<0.0001)$ and was positively associated with self-reported likings. The edible plate waste was 88 (SD 80) $\mathrm{g}$ for the NND period and 43 (SD 60) $\mathrm{g}$ for the packed lunch period whereas the relative edible plate waste was no different between periods for meals having waste $(n$ 1050). Edible plate waste differed between menus $(P<0.0001)$, with more waste on soup days $(36 \%)$ and vegetarian days $(23 \%)$ compared with the packed lunch period. Self-reported likings were negatively associated with percentage plate waste $(P<0 \cdot 0001)$. The study suggests that portion sizes need to be considered in new school meal programmes. New strategies with focus on reduction of plate waste, children's likings and nutritious school meals are crucial from both a nutritional, economic and environmental point of view.

Key words: Edible plate waste: School meals: Packed lunches: Food liking

Children spend more time in schools than in any other environment away from home and while education is the primary role of the schools, the schools cannot entirely achieve their mission if children are not alert and ready to learn which are related to a healthy diet and physical activity ${ }^{(1)}$. Additionally, schools are important settings to improve access to healthier foods for preventing overweight, obesity and chronic diseases in the long term and to reach children across all ethnic and socio-economic groups ${ }^{(1-3)}$. Several school- based interventions have documented that it is possible to influence school children's dietary habits positively ${ }^{(2-4)}$.

The majority of Danish children do not eat in accordance with the national dietary guidelines, but consume too many energy-dense and nutrient-poor foods, too much sugar, salt, saturated fat and fat, and too little wholegrain, fruits, vegetables and fish ${ }^{(5-8)}$. Furthermore, the social differences in overweight and obesity have widened from 2000-2002 to 2005-2008, especially for boys of parents with a short education ${ }^{(9)}$.

Abbreviations: NND, new Nordic diet; OPUS, optimal well-being, development and health for Danish children through a healthy new Nordic Diet [English translation].

* Corresponding author: Anne Vibeke Thorsen, email avth@food.dtu.dk

(C) The Author(s) 2015. This is an Open Access article, distributed under the terms of the Creative Commons Attribution licence (http://creativecommons.org/licenses/by/3.0/), which permits unrestricted re-use, distribution, and reproduction in any medium, provided the original work is properly cited. 
Denmark has no national school food programme and three out of four Danish children bring a packed lunch from home as only a few schools have canteens ${ }^{(5)}$. Typically, a packed lunch consists of open-faced sandwiches on Danish-style rye bread with liver paste or other types of meat products and sometimes vegetables and fruit ${ }^{(5)}$. The OPUS School Meal Intervention was conducted comparing new Nordic diet (NND) meals with packed lunches from home in order to investigate the health impact of serving school meals based on the NND ${ }^{(10)}$. Translated into English, OPUS is an abbreviation for 'optimal well-being, development and health for Danish children through a healthy new Nordic Diet'.

Fundamental for NND dietary principles are that meals are palatable, environmentally friendly and largely based on food originating from the Nordic region ${ }^{(11)}$. Another key principle for the NND is to obtain less waste from the overall food production which includes an appropriate food intake as well as minimising food waste because food wasted affects not only the cost of the meal but also the climate footprint $^{(11-13)}$

Plate waste is generally defined as the quantity of edible food served that is uneaten ${ }^{(14)}$. Some plate waste is unavoidable, given the diversity of children and daily variation in appetite but excessive plate waste may indicate unnecessary costs of a meal programme and furthermore plate waste may have negative impact on the climate footprint ${ }^{(12,14,15)}$. Additionally, the potential health effects of the NND in a free-living population are dependent on the NND meals being actually eaten and not just served.

The measurement of food waste of different school lunch formats is new - and timely with the current awareness of food waste overall in a dietary sustainability context. Furthermore, to our knowledge, no randomised controlled trial has assessed the impact of introducing a whole new full meal concept covering the whole lunch, while at the same time performing careful measurements of children's plate waste.

The aim of the present study was to investigate whether the amount of food intake and total and relative edible plate waste differed between packed lunches from home and school meals served based on NND principles. A further objective was to examine how food intake and food waste at the two types of meals are associated with the children's likings of the meals.

\section{Methods}

\section{Study design and recruitment}

The OPUS School Meal Study is a cluster-randomised controlled unblinded cross-over study. In two 3-month periods 3rd- and 4th-grade children (aged 8-11 years) from nine selected municipal schools received school meals based on the NND and their usual packed lunch (control) in random order during the school year 2011-2012. A number of measurements were performed before the start of the first dietary period (baseline), at the end of the first dietary period (month 3 ) and at the end of the second dietary period (month 6). The study design and recruitment to the OPUS School Meal Study including this plate waste study have previously been described in detail ${ }^{(10)}$.

Two of the nine selected schools were randomly assigned to the present study of food intake and plate waste. The NND meals were produced locally at each school by trained chefs and kitchen personnel hired for the study and small groups of children participated in the cooking every day.

The packed lunches were eaten in the classrooms whereas the NND meals were prepared and served in a cafeteria set up for the purpose of the study. Supervised by the OPUS kitchen personnel, four to six alternating pupils served the ad libitum hot NND meals at the buffet. The children were encouraged to taste all food served and keep a reasonable plate distribution with vegetable and starchy food filling the majority of the plate ${ }^{(16)}$. The adult kitchen personnel supervised four to six alternating children who helped to serve the NND meals.

The guidelines and dietary composition and nutrient content of NND have been described in detail by Mitril et al. ${ }^{(11,17)}$. The NND menus contained more berries, cabbage, root vegetables, legumes, fresh herbs, potatoes, wild plants and mushrooms, whole grains, nuts, fish, shellfish and less meat than the average Danish diet ${ }^{(10,11,17)}$. The energy density of the NND lunch was on average $560 \mathrm{~kJ} / 100 \mathrm{~g}$ whereas the energy density of the packed lunch on average was 740 $\mathrm{kJ} / 100 \mathrm{~g}$.

A 3-week NND menu was developed and served for each of the three seasons (autumn, winter and spring). The menu plan for the NND meals were the following: Monday: soup and some fruit for dessert; Tuesday: meat; Wednesday: vegetarian dish and a dessert; Thursday: fish; Friday: buffet-style with calculated leftovers from the menu every day, Monday to Thursday. Each weekly schedule had a balance between different categories of ingredients consistent with the nutritional recommendations, and took into account the feasibility in preparing the meals and incorporating calculated leftovers from the menu every day, Monday to Thursday, to be utilised on Fridays. Tap water was served and available at the tables with the NND lunch meals.

The NND meals were free of charge for all 3rd- and 4th-grade children at the participating schools. The lunch break was 20 min when having a packed lunch but increased to $25 \mathrm{~min}$ at school $\mathrm{A}$ and from $25 \mathrm{~min}$ up to $40 \mathrm{~min}$ at school $\mathrm{B}$ when getting the NND.

\section{Food intake and edible plate waste}

The amount of food intake and edible plate waste at lunch were measured for five consecutive days by weighing each child's lunch before and after eating. To ensure that the children had time to get used to the new NND diet the measurements were taken at the end of the intervention period. The method used was developed by Sabinsky et al. ${ }^{(18)}$ and adapted by Thorsen \& Biltoft-Jensen ${ }^{(19)}$. Beverages were not included in this study. Food intake and edible plate waste $=5 \mathrm{~g}$ were regarded as no intake or no waste. 
Recording food intake and edible plate waste for packed lunch from home

Before lunch break solid polystyrene plates and trays tagged with class, date and identity numbers were distributed to all children in the classrooms. The children were asked to unpack their packed lunches from home, place their food on the plate and to separate items and open up the sandwiches, so all food items would be observable. The children brought their food to the weighing station outside the classroom where a trained assistant weighed the plate (Vera 67002, with a precision of $\pm 1 \mathrm{~g}$; Soehnle) and then to the photograph station where another trained assistant took a photograph of the plate (Nikon COOLPIX S 210 digital camera). When the children had finished eating the procedure was repeated. Any package or wrapping that was weighed the first time (yoghurt and noodle cups, muesli bar wrappings, etc.) was left on the plate and also weighed the second time. If the plate waste also included non-edible food items (fruit peel, wrapping, etc.) these were removed and the plate and edible waste were weighed again. The photographs were used for confirming the weight data. The weights of the plates were subtracted from the pre- and post-measures and also the served weight was adjusted for non-edible items. The relative edible plate waste was also calculated by comparing the edible plate waste with the total amount of edible food served.

\section{Recording food intake and edible plate waste for the new Nordic diet lunch}

The same procedure as described above for packed lunches brought from home was used except that the measurements were taken near the buffet. If the children chose to have a second serving the procedure was repeated and the NND food was weighed and photographed before and after eating.

\section{Self-reported smiley rating from the Web-based Dietary Assessment Software for Children}

During the OPUS School Meal Study, dietary assessment at baseline, and at dietary periods 1 and 2 were obtained from each child using the Web-based Dietary Assessment Software for Children (WebDASC) ${ }^{(20)}$. A self-reported smiley rating was included in the WebDASC to measure the children's liking of the lunch on a scale from 1 to 5 $(1=$ really bad, $2=$ bad, $3=$ okay, $4=$ good and $5=$ really good). Since only two packed lunches were rated really bad and two packed lunches were rated bad these two groups were combined.

\section{Background information}

At baseline each child together with at least one parent or custody holder underwent a 2 -h in-depth interview by a trained interviewer including instructions in using the dietary assessment tool, either at the school or at home ${ }^{(10)}$. The interview included background information like sex, age group and socio-economic status of the household. The educational level of the household was categorised according to the standard classifications of Statistics Denmark, i.e. as the highest level of education achieved by a parent in the household ${ }^{(21)}$. The variable was divided into six different groups depending on the educational level (lower secondary education; upper secondary education or equivalent; vocational education; short higher education; bachelor's degree or equivalent; and master's degree).

\section{Data analyses and statistics}

Analyses included standard descriptive statistics. Two types of outcomes were analysed: binary (i.e. waste/no waste); and continuous (i.e. weight of food intake and edible plate waste). Data were therefore modelled in two steps with regard to edible waste: first, a logistic regression model with random effects fitted for the probability of waste/no waste; and second, a model fitted for either total food intake or total or relative edible plate waste data ${ }^{(22)}$.

To analyse the percentage edible plate waste (in lunches having edible plate waste) random-effects models were used for intake and waste $(\mathrm{g})$. First a model was fitted with two random effects (child and class) to take the design into account. The model was also adjusted for school, sex, grade, dietary period, household education level and intervention.

Since the study had a cluster-randomised cross-over design, classes were randomised to receive the NND either in the first or in the second dietary period with five measurements on each child in each period. This data structure resulted in two random effects: a child effect and a class effect (the whole class is randomised together). Two schools were analysed in the present study and treated as a fixed effect for both classes and schools. All models included school, sex, year group and household education level as fixed effects in the analysis. The assumptions underlying the models were tested using residual plots and QQ plots. It was necessary to transform the continuous outcome of interest using the logarithm but the results are presented on the original scale. The assumptions behind the model to analyse percentage edible plate waste were tested using residual plots and it turned out that the square root transformation gave the best results. The results are, however, expressed on the original scale as differences in percentage waste $^{(23)}$.

SAS version 9.3 (SAS Institute, Inc.) was used for all statistical analyses. The significance level was chosen as 0.05.

\section{Results}

Table 1 shows the descriptive statistics of the 187 children from the two municipal schools participating in the present study, $48 \%$ from the $3 \mathrm{rd}$ and $52 \%$ from the 4 th grade. Of the children, $45 \%$ were boys and $55 \%$ were girls. All in all, 1558 lunches were analysed.

One child had no information about household education level and was excluded from the analyses. 


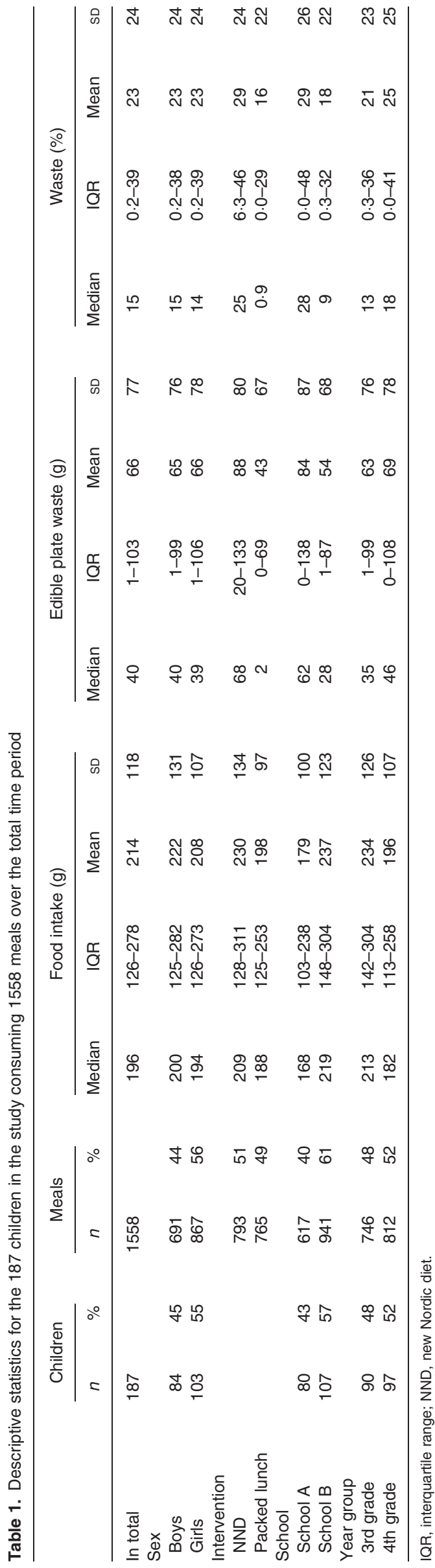

\section{Food intake}

The median and mean food intake, edible plate waste and percentage edible plate waste are shown in Table 1 . The lunch intake for the children was 230 (SD 134) g during the NND period and 198 (SD 97) g during the control period (packed lunch) (Table 1). The mean portion size (the amount of food served) was $318 \mathrm{~g}$ for the NND compared with packed lunches $(241 \mathrm{~g})$. The food intake at school A was 179 (SD 100) g compared with school B (237 (SD 123) g) (Table 1).

Table 2 lists the descriptive statistics for liking of the different menus ( $n$ 905). Of the NND meals the leftovers, vegetarian and cake and meat all had high likings with more than $39 \%$ of the children rating the meal as really good. Soup was liked the least among the NND menus being rated as really bad/bad (18\% meals). Regarding the packed lunch, $46 \%$ of meals were rated as really good and only $1 \%$ of meals were rated as really bad or bad.

Table 3 (model 1) shows that lunch intake was on average $6 \%$ larger ( $\mathrm{g} /$ lunch) $(95 \%$ CI 1.01, 1.12) for children having the NND compared with the period when they had packed lunch $(P=0.02)$ ( $n$ 1543). The NND lunch intake varied with the menu $(P<0 \cdot 0001)$ (Table 3, model 2$)$. When having soup the children had on average a $22 \%$ higher lunch intake (95\% CI 1.12, 1.32) compared with packed lunches. Also on the vegetarian day the food intake was $38 \%$ higher $(95 \%$ CI $1 \cdot 26,1 \cdot 51)$ whereas the lunch intake was $14 \%$ lower $(95 \%$ CI $0.79,0.94)$ on the fish day compared with packed lunches.

In Table 3 (model 3) the children's self-reported ratings of the lunch were compared with the lunch type ( $n$ 1329). The effect of the NND was increased when ratings were taking into account, so when sex, school, year group, household education, period and rating were included as fixed effects in the analysis the intake increased $13 \%$ during the NND compared with the period with a packed lunch $(95 \%$ CI 1.07, 1.20) (Table 3, model 3). The amount of food intake increased with the rating of the lunch $(P<0.0001)$. If a lunch was rated really good the food intake was $59 \%$ larger than when a lunch was rated as really bad or bad (95\% CI 1.36, 1.85).

\section{Edible plate waste}

Looking at all lunch meals $(n$ 1558) in Table 1 , the edible plate waste was 88 (SD 80) $\mathrm{g}$ for the NND, resulting in a $29 \%$ edible plate waste; for packed lunches the edible plate waste was 43 (SD 60) g, resulting in a $16 \%$ edible plate waste.

A total of 1558 lunches were analysed and, of these, 498 lunches $(26 \%)$ had no edible plate waste. Of the 498 meals without edible plate waste, $102(20.5 \%)$ were NND meals and $396(79.5 \%)$ were packed lunches (results not shown). Also, children from the 3rd grade wasted $9 \%$ less than children in the 4th grade after adjusting for school, sex, education, period and intervention (results not shown). The two schools performed differently; school A had $14 \%$ more edible plate waste compared with school B (results not shown).

Table 4 (model 1) shows no significant difference between the NND and packed lunches considering only the plates having edible plate waste $(n 1055)(P<0 \cdot 3506)$. However, Table 4 
Table 2. Descriptive statistics for likings of the new Nordic diet meals and packed lunch for 905 meals (Numbers and percentages)

\begin{tabular}{|c|c|c|c|c|c|c|c|c|c|}
\hline & \multicolumn{2}{|c|}{ Really bad/bad } & \multicolumn{2}{|c|}{ Okay } & \multicolumn{2}{|c|}{ Good } & \multicolumn{2}{|c|}{ Really good } & \multirow[b]{2}{*}{ In total } \\
\hline & $n$ & $\%$ & $n$ & $\%$ & $n$ & $\%$ & $n$ & $\%$ & \\
\hline Soup and fruit slices & 24 & $18 \cdot 0$ & 37 & 27.8 & 45 & 33.8 & 27 & $20 \cdot 3$ & 133 \\
\hline Meat & 8 & $7 \cdot 1$ & 21 & $18 \cdot 6$ & 40 & 35.4 & 44 & 38.9 & 113 \\
\hline Vegetarian and cake & 5 & 4.0 & 21 & $17 \cdot 0$ & 47 & 37.9 & 51 & $41 \cdot 1$ & 124 \\
\hline Fish & 8 & $7 \cdot 3$ & 23 & 18.5 & 42 & 38.2 & 37 & $33 \cdot 6$ & 110 \\
\hline Leftovers & 1 & 1.0 & 24 & $23 \cdot 3$ & 35 & $36 \cdot 1$ & 43 & 41.7 & 103 \\
\hline Packed lunch & 4 & 1.2 & 38 & 11.8 & 133 & 41.3 & 147 & $45 \cdot 7$ & 322 \\
\hline Total & 50 & 5.5 & 164 & $18 \cdot 1$ & 342 & 37.8 & 349 & 38.6 & 905 \\
\hline
\end{tabular}

(model 2) shows that edible plate waste differed according to the menu; on the soup day the children had $36 \%$ (95\% CI $1.15,1.60)$ more edible plate waste than during the period with packed lunches. The vegetarian and cake menu day had significantly more waste (23\%) (95\% CI 1.04, 1.45) whereas there was less waste on the fish day (18\% decrease) (95\% CI $0.69,0.97)$ compared with the period where the children consumed packed lunches. Plate waste on the leftover day and on the meat day was comparable with plate waste on packed lunch days.

Also, the amount of edible plate waste was negatively associated with the rating of the lunch as shown in Table 4 (model 3) $(P<0 \cdot 0001)$. If a lunch was rated as really bad or bad then the plate waste on average was $69 \%$ larger $(95 \%$ CI $1 \cdot 29,2 \cdot 21)$ compared with a lunch rated as really good (Table 4, model 3).

Table 5 shows the relative edible plate waste (compared with the total amount of food served) for the NND and packed lunches. Table 5 (model 1) shows no significant differences between the percentage edible plate waste of the NND compared with packed lunches when looking at the plates having

Table 3. Results from three linear mixed models for the effect of the new Nordic diet (NND) on lunch intake*

(Estimates and $95 \%$ confidence intervals)

\begin{tabular}{|c|c|c|c|}
\hline & Estimate & $95 \% \mathrm{Cl}$ & $\begin{array}{c}\text { Test for no } \\
\text { effect: } P\end{array}$ \\
\hline \multicolumn{4}{|l|}{ Model 1 ( $n$ 1543) } \\
\hline NND & 1.06 & $1.01,1.12$ & 0.0229 \\
\hline Packed lunch & 1 & & \\
\hline \multicolumn{4}{|l|}{ Model 2 ( $n$ 1543) } \\
\hline Soup & $1 \cdot 22$ & $1 \cdot 12,1.32$ & $<0.0001$ \\
\hline Meat & 1.00 & $0.91,1.10$ & \\
\hline Vegetarian and cake & $1 \cdot 38$ & $1.26,1.51$ & \\
\hline Fish & 0.86 & $0.79,0.94$ & \\
\hline Leftovers & 0.93 & $0.85,1.01$ & \\
\hline Packed lunch & 1 & & \\
\hline \multicolumn{4}{|l|}{ Model 3 (n 1329) } \\
\hline NND & $1 \cdot 13$ & $1.07,1.20$ & $<0.0001$ \\
\hline Packed lunch & 1 & & \\
\hline Lunch rating: really bad/bad & 1 & & $<0.0001$ \\
\hline Lunch rating: okay & 1.07 & $0.92,1.26$ & \\
\hline Lunch rating: good & 1.40 & $1.21,1.63$ & \\
\hline Lunch rating: really good & 1.59 & $1.36,1.85$ & \\
\hline
\end{tabular}

Model 1, initial model for the effect of the NND; model 2, taking the menu into account; model 3 , adjusting for liking.

* School, sex, year group, household education and dietary period were included as fixed effects in the analysis. edible waste ( $n$ 1055) $(P=0.9280)$. No significant effect of sex was seen on percentage edible plate waste, but age group was highly significant on percentage plate waste $(P<0 \cdot 0001)$ (results not shown).

Looking at the different menus, the percentage waste (the relative plate waste) was $3 \%$ larger on soup days $(95 \%$ CI $-0.38,6.81)$ than with packed lunches. The percentage edible plate waste did not differ significantly in the intervention groups $(P=0 \cdot 1339)$.

Rating of lunch is highly significant for the percentage plate waste $(P<0 \cdot 0001)$. If a lunch was rated as really bad or bad then the percentage plate waste was $17 \%$ higher compared with a lunch rated as really good (95\% CI 11.49, 22.92) when including school, sex, year group, household education, dietary period and intervention as fixed effects ( $n$ 902) (Table 5, model 3).

As shown in Table 1 the average food intake for the NND was in fact higher (230 (SD 134) g/d) compared with packed lunches (198 (SD 97) g/d). Together with the higher edible plate waste in the NND period of 88 (SD 80) g compared

Table 4. Results from three linear mixed models for the effect of the new Nordic diet (NND) on edible plate waste* (Estimates and $95 \%$ confidence intervals)

\begin{tabular}{llll}
\hline & Estimate & $95 \% \mathrm{Cl}$ & $\begin{array}{c}\text { Test for no } \\
\text { effect: } P\end{array}$ \\
\hline $\begin{array}{l}\text { Model } 1 \text { ( } n \text { 1055) } \\
\quad \text { NND }\end{array}$ & 1.06 & $0.94,1.19$ & 0.3506 \\
$\quad$ Packed lunch & 1 & & \\
Model 2 $(n$ 1055) & & & \\
$\quad$ Soup & 1.36 & $1.15,1.60$ & $<0.0001$ \\
$\quad$ Meat & 1.01 & $0.85,1.20$ & \\
$\quad$ Vegetarian and cake & 1.23 & $1.04,1.45$ & \\
$\quad$ Fish & 0.82 & $0.69,0.97$ & \\
Leftovers & 0.91 & $0.77,1.08$ & \\
$\quad \begin{array}{l}\text { Packed lunch } \\
\text { Model 3 ( } n \text { 902) }\end{array}$ & 1 & & \\
$\quad$ NND & 1.01 & $0.89,1.15$ & 0.8586 \\
$\quad$ Packed lunch & & & \\
$\quad$ Lunch rating: really bad/bad & 1.69 & $1.29,2.21$ & $<0.0001$ \\
$\quad$ Lunch rating: okay & 1.33 & $1.12,1.59$ & \\
$\quad$ Lunch rating: good & 1.05 & $0.92,1.21$ & \\
$\quad$ Lunch rating: really good & 1 & & \\
\hline
\end{tabular}

Model 1, initial model for the effect of the NND; model 2, taking the menu into account; model 3 , adjusting for liking.

* School, sex, year group, household education and dietary period were included as fixed effects in the analysis for meals having edible plate waste. 
Table 5. Results from three linear mixed models for the effect of the new Nordic diet (NND) on percentage edible plate waste*

(Estimates and $95 \%$ confidence intervals)

\begin{tabular}{lccc}
\hline & Estimate & $95 \% \mathrm{Cl}$ & $\begin{array}{c}\text { Test for no } \\
\text { effect: } P\end{array}$ \\
\hline Model 1 ( $n$ 1055) & & & \\
$\quad$ NND & -0.12 & $-2.64,2.41$ & 0.9280 \\
Packed lunch & 0 & & \\
Model 2 ( $n$ 1055) & & & 0.1339 \\
Soup & -0.12 & $-2.64,2.41$ & \\
Meat & 3.22 & $-0.38,6.81$ & \\
Vegetarian and cake & -0.47 & $-4.36,3.42$ & \\
Fish & -2.09 & $-5.76,1.57$ & \\
Leftovers & -2.14 & $-5.98,1.70$ & \\
Packed lunch & 0 & & $<.1970$ \\
Model 3 ( $n$ 902) & & & \\
NND & -1.78 & $-4.49,0.93$ & \\
Packed lunch & 0 & & \\
Lunch rating: really bad/bad & 17.21 & $11.49,22.92$ & $<001$ \\
Lunch rating: okay & 11.83 & $8.09,15.57$ & \\
Lunch rating: good & 4.03 & $1.07,6.99$ & \\
Lunch rating: really good & 0 & & \\
\hline
\end{tabular}

Model 1, initial model for the effect of the NND; model 2, taking the menu into account; model 3 , adjusting for liking.

* School, sex, year group, household education and dietary period were included as fixed effects in the analysis for meals having edible plate waste.

with the packed lunch (43 (SD 67) g), this clearly shows an expected discrepancy. However, when the edible plate waste compared with the packed lunch was adjusted for the confounders the results showed clearly that the edible plate waste was significantly different for the meals where the meals with soup, vegetarian/cake, and fish were served (Table 4). These differences disappeared when the edible plate waste was expressed as a percentage of the served meal weight (Table 5). So the larger meals in weight and waste of the NND meals are taken into account.

\section{Discussion}

In the present study the children receiving the NND had on average a $6 \%$ larger lunch intake compared with the period when they had packed lunches. At the same time the average edible food waste was higher for the NND (mean $88 \mathrm{~g}$ ) than for packed lunches (mean $43 \mathrm{~g}$ ). Looking at the relative edible plate waste (comparing the edible plate waste with the total amount of food served) the children on average had $29 \%$ edible plate waste when eating the NND compared with $16 \%$ when eating packed lunches. This difference is mainly due to the fact that more children had edible plate waste in the NND group than in the packed lunch group. Among those having plate waste no significant difference was seen between having the NND and having packed lunches.

The soup day and the vegetarian and cake day were the days with the highest food intake and having the highest plate waste, indicating that the portion size needs to be adjusted for these meals.

When adjusting the portion sizes also the energy density of the food needs to be considered. In order to have an appropriate energy intake children need to eat bigger portion sizes of the NND having a lower energy density (in average $560 \mathrm{~kJ} / 100 \mathrm{~g}$ ) compared with packed lunches $(740 \mathrm{~kJ} / 100 \mathrm{~g}$ ) which might be difficult for a child in a short lunch break and therefore resulting in a large plate waste for the NND compared with packed lunches ${ }^{(16)}$.

In a report on plate waste for Swedish school canteens the plate waste varied from 5 to $80 \mathrm{~g}$ per portion, depending on how much the children liked the food, measuring methods, conditions at the school and attitudes among the children and the staff ${ }^{(24)}$. Compared with the Swedish data the percentage edible plate waste for the NND (29\%; equivalent to $88 \mathrm{~g}$ ) meal was high. However, the percentage edible plate waste varied according to the NND menu, with most waste on a soup day and the smallest amount of waste on fish day.

Also, Buzby \& Guthrie ${ }^{(14)}$ found that plate waste varied with meal type, with vegetables and salad tending to be the most wasted items in the National School Lunch Program in the USA. The data were collected from 1991 to 1992 by 3350 students using a $24 \mathrm{~h}$ recall (no lunches from home). In that study, plate waste varied by age and sex; girls wasted more than boys. Children under 11 years of age wasted 15 $\%$ of their food while older children wasted less (11- to 14-year-olds wasted $12 \%$ ). In the present study we found no significant effect of sex on percentage edible plate waste, but age group was highly significant on percentage plate waste $(P<0 \cdot 0001)$.

Baik \& Lee ${ }^{(25)}$ found that school children (aged 6-9 years old) had plate waste from 15 to $19 \%$ of the school lunch being served. In the present study the edible plate waste was $29 \%$ for the NND, which is almost double the percentage compared with Baik \& Lee's finding $(15-19 \%)^{(25)}$ and the finding by Buzby \& Guthrie $(12-15 \%)^{(14)}$.

Bergman et al. ${ }^{(26)}$ found that meal scheduling could influence plate waste; students ate more and wasted less when eating lunch later during the school day and preferably after recess. In the present study the lunch break was longer when having the NND compared with packed lunches; up to $40 \mathrm{~min}$ lunch break at school $\mathrm{B}$ and $25 \mathrm{~min}$ at school A. This might explain part of the $6 \%$ higher intake for the NND compared with packed lunches and also the higher food intake at school B compared with school A.

Liking school meals seems to be essential to reduce edible plate waste. In the present study the percentage edible plate waste was $17 \%$ larger when the children rated the meal as really bad or bad compared with really good $(P<$ 0.001). Maybe not surprisingly, packed lunches were rated higher than the different NND menus since parents normally would prepare a packed lunch that their children like (Table 2).

Nevertheless, an average percentage plate waste at $29 \%$ for the NND is not sustainable compared with other school meal systems having $12-20 \%$ plate waste ${ }^{(14,24,25)}$. On the other hand, NND meals are very different from packed lunch so it might take more than 3 months for the children to familiarise to the NND and to adjust portion sizes. The latter is supported by the amount of served food being almost $80 \mathrm{~g}$ larger for the NND (mean $=318 \mathrm{~g}$ ) compared with packed lunches 
(mean $=241 \mathrm{~g}$ ), which might be a result of the not adjusted portion sizes and not simply because the children did not like the NND meals. In order to make the NND meals sustainable it is crucial to ensure that the children eat in accordance with the dietary recommendations and guidelines including appropriate portion size.

Plate waste studies are expensive and time consuming in particular if the foods are weighed at the beginning and the end of a meal. Other methods such as visual estimates by trained observers or $24 \mathrm{~h}$ recalls by children do not take into account the actual plate waste ${ }^{(14,15)}$. Cohen et al. ${ }^{(15)}$ found the weighing method to be disruptive to normal lunch procedure and observed and estimated the waste instead. In the present study the setting of the NND meals was very different from the normal lunch procedure so it was decided to use the weighing method as this was considered the most accurate method.

One of the principles of the NND is to be environmentally friendly, and minimising edible plate waste is important because food wasted affects not only the cost of the meal but also the climate footprint ${ }^{(12,15)}$. When analysing the effect of climate optimising for the NND meals and the recommended Nordic diet these diets were found to be $20 \%$ more climate friendly than the average Danish diet but these calculations did not include the $29 \%$ edible plate waste for NND meals found in the present study ${ }^{(12,13)}$.

Interventions in real-life settings are complex systems that interact dynamically with the key stakeholders and therefore the intervention has to be tailored to the needs of the particular school environment in which it is implemented ${ }^{(27-29)}$. In the present study large differences were seen between the two schools and between the two year groups. One strategy to lower plate waste would be to tailor the intervention at the specific school taking into account the specific challenges at the school. Another strategy could be to network between the schools about the successes and challenges. Children from the 3rd grade wasted $9 \%$ less than children in the 4th grade after adjusting for school, sex, education, period and intervention which is in contrast to the findings of Buzby \& Guthrie $^{(14)}$. The 4th graders seemed less guided by the teachers at lunch and often in a hurry to play, whereas the $3 \mathrm{rd}$ graders followed more willingly the guidelines of the teachers and the encouragements by chefs at the cafeterias. The two schools performed differently; school A had $14 \%$ more edible plate waste compared with school B. One explanation for more plate waste could be that school A had a shorter lunch break than school B or maybe because the key stakeholders at school B took more ownership of the OPUS School Meal Study than at school A.

Serving smaller portion sizes would be another obvious strategy to reduce plate waste since food intake and plate waste were higher for the NND compared with packed lunch, however, this could result in insufficient energy intake for some children. In the present study it was seen that the 3 rd graders were served larger portions than the 4th graders which might explain the 3rd graders higher food intake but not the lower $9 \%$ lower plate waste (Table 1). Also Andersen $e t$ al ${ }^{(30)}$ find that 3 rd graders have a higher food intake than 4th graders in a study of all nine schools even though data were collected using a food record.

Strategies to reduce plate waste and getting children to like and eat a nutritious school meal would be interesting from not only a nutritional and economic point of view but also an environmental point of view. An earlier study of a Danish school-based meal programme showed that the nutritional quality of lunch was improved when the children had lunch provided by the school instead of packed lunch from home ${ }^{(31)}$. Also an American school cafeteria study showed an impact on the nutritional quality of the school meals when hiring a chef at the school cafeteria to make the meals not only nutritious but also palatable ${ }^{(32)}$. Another Danish school meal programme in Copenhagen (providing an average of 3700 meals daily) served healthy and tasty meals at a price that all children could afford in order to make equality in health by differentiating the price of the meal depending on the parents' income level ${ }^{(33)}$.

A tailored long-term school lunch programme might be a way to get children in school to eat in accordance with the dietary guidelines including proper portion sizes and thereby diminishing food waste and maybe some of the socioeconomics differences in food intake that are found among school-aged children.

The present study was designed in such a way that the 4th grade at school A received the NND in period 1 and the 3rd grade in period 2, while at school B it was the other way round. Therefore it was not possible to distinguish between an interaction between the NND and period and an interaction between year group and school. Also seasonality was not accounted for in the data analysis. Another limitation of the study was that the eating environment when eating packed lunches was not similar to that of the NND meals, thus favouring the NND meals (longer lunch breaks and nicer eating environments when having the NND compared with packed lunches). On the other hand, packed lunches could also have been affected by the parents/children knowing of the measurement being performed. In the present study total food intake $(\mathrm{g})$, edible plate waste $(\mathrm{g})$ and the relative plate waste (compared with the total amount of served food) were analysed whereas the nutrient content of the meals eaten were not analysed. The dietary effects of the NND were evaluated in a separate paper by Andersen $e t$ al. ${ }^{(30)}$. The purpose of the OPUS School Meal Study was to test the effect of the NND on multiple outcomes; and the study was designed so the meals were free of charge for the participating children. In a real-life setting a school meal programme will not be free. Another paper will address the cost of the OPUS School Meal Study.

Some strengths of the study are the study design, being a cluster-randomised cross-over design, and the use of advanced statistical analyses taking advantage of the current clusterrandomised cross-over design in a two-step logistic regression model brings convincing results giving the study high power; furthermore, the assessments were taken during a period of $5 \mathrm{~d}$ on the same children. Another strength is that the measurements were taken after 3 months of having the NND meals, giving time for the children to get used to the NND 
meals, which were very different from the usual packed lunch from home. The present study demonstrates convincingly that school children 8-11 years of age are willing to consume more meals that may be unknown to them than described in the literature. We consider that the use of liking measurements of whole meals is novel - and a step forward from the liking measurements of individual foods when taking a public health nutrition perspective and the liking rating is effective as the food intake was $59 \%$ larger when the meals were rated really good compared with when the lunch was rated bad or really bad.

Finally, plate waste studies that weigh foods at the beginning and end of meals are considered to provide detailed, accurate information $^{(15)}$.

\section{Conclusion}

In conclusion, this cross-over school intervention study showed that the children consumed a significantly higher amount of food at lunch time during the NND period compared with the period on packed lunches from home. The average edible food waste was significantly higher during the NND period compared with the packed lunch period looking at the absolute amounts, whereas the difference in percentage waste was not statistically significant for the NND and packed lunch for meals having plate waste. The study showed that the children's likings of the school meals were inversely associated with the edible plate waste, indicating that likings are essential in attempts to reduce edible plate waste in this age group. Even though some plate waste is inevitable in a school setting, the present study suggests that careful measuring of plate waste together with knowledge of the children's likings can be used to form new strategies to reduce plate waste and getting children to eat nutritious school meals in an economic and environmentally sustainable way.

\section{Acknowledgements}

Thanks to all the participating children, the teachers, the principals and the kitchen personnel for their cooperation, helpfulness and patience during data collection. All the students and trainees from Metropol University College, Copenhagen, University of Copenhagen and several colleagues from the Division of Nutrition, the National Food Institute, Technical University of Denmark are thanked for their help measuring total food intake and food waste. Last, but not least, dietitian Karin Hess Ygil is thanked for calculating the energy density of the NND menus.

The OPUS project ('Optimal well-being, development and health for Danish children through a healthy New Nordic Diet') is supported by a grant from the Nordea Foundation (grant no. 02-2010-0389). The Nordea Foundation had no role in the design, analysis or writing of this article.

The study protocol was approved by the Danish National Committee on Biomedical Research Ethics (H-1-2010-124) and the trial was registered in the database www.clinicaltrials. gov (no NCT 01457794).
Author contributions: A. V. T. and A. B. J. designed the study and formed the research questions. A. V. T. and L. M. C. carried out the study. E. W. A. undertook the statistical analyses. A. V. T., A. D. L. and E. W. A. analysed the data and discussed the study results. A. V. T. drafted the manuscript. A. D. L., E. W. A., A. B. J., R. A., C. T. D., K. F. M. and I. T. revised the draft manuscript.

The authors do not have any conflict of interest to declare.

\section{References}

1. Story M, Nannay MS \& Schwartz MB (2009) Schools and obesity prevention: creating school environments and policies to promote healthy eating and physical activity. Milbank Q 87, 71-100.

2. Waters E, de Silva-Sanigorski A, Hall BJ, et al. (2011) Interventions for preventing obesity in children, version 3. The Cocbrane Database of Systematic Reviews 2011, issue 12, CD001871. http://www.mrw. interscience.wiley.com/cochrane/clsysrev/articles/CD001871/frame. html

3. Summerbell CD, Waters E, Edmunds LD, et al. (2005) Interventions for preventing obesity in children, version 2. The Cocbrane Database of Systematic Reviens 2005, issue 3, CD001871. http://onlinelibrary.wiley.com/doi/10.1002/14651858.CD001871. pub2/abstract

4. Knai C, Pomerleau J, Lock K, et al.(2006) Getting children to eat more fruit and vegetables: a systematic review. Prev Med 42, 85-95.

5. Christensen L, Kørup K, Trolle E, et al. (2012) Born og unges mailtidsvaner 2005-2008 (Dietary Habits of Children and Adolescents 2005-2008). Søborg, Denmark: Division of Nutrition, National Food Institute, Technical University of Denmark.

6. Astrup A, Andersen NL, Stender S, et al. (2005) Kostrådene (Dietary Guidelines). Copenhagen, Denmark: Danish Institute for Food and Veterinary Research and Danish Nutritional Council.

7. Becker W, Lyhne N, Pedersen AN, et al. (2004) Nordic Nutrition Recommendations, 4th ed. Integrating Nutrition and Physical Activity. Nord 2004:13. Copenhagen, Denmark: Nordic Council of Ministers.

8. Pedersen AN, Fagt S, Groth MV, et al. (2010) Kostvaner i Danmark 2003-2008 (Dietary Habits in Denmark 2003-2008). Søborg, Denmark: Division of Nutrition, National Food Institute, Technical University of Denmark.

9. Groth MV, Christensen LM, Knudsen VK, et al. (2013) Sociale forskelle $i$ borns og unges kostvaner, fussile aktivitet og overvagt og voksnes kostvaner (Social Differences in Children's Dietary Habits, Physical Activity and Overweight and Adults' Dietary Habits). Søborg, Denmark: Division of Nutrition, National Food Institute, Technical University of Denmark.

10. Damsgaard CT, Dalskov SM, Petersen RA, et al. (2012) Design of the OPUS School Meal Study: a randomised controlled trial assessing the impact of serving school meals based on the new Nordic diet. Scand J Public Health 40, 693-703.

11. Mithril C, Dragsted LO, Meyer C, et al. (2012) Guidelines for the new Nordic diet. Public Health Nutr 15, 1941-1947.

12. Thorsen AV, Mogensen L, Jørgensen MS, et al. (2012) Klimaorienterede kostråd (Climate-Friendly Dietary Guidelines). Søborg, Denmark: Division of Nutrition, National Food Institute, Technical University of Denmark.

13. Saxe H, Larsen TM \& Mogensen L (2013) The global warming potential of two healthy Nordic diets compared with the average Danish diet. Climatic Change 116, 249-262.

14. Buzby JC \& Guthrie JF (2002) Plate waste in school nutrition programs: final report to Congress. Washington, DC: Economic Research Service, USDA. http://www.ers.usda.gov/media/ 887982/efan02009.pdf (accessed February 2011).

15. Cohen JFW, Richardson S, Austin SB, et al. (2013) School lunch waste among middle school students: nutrients consumed and food waste costs. Am J Prev Med 44, 114-121. 
16. Camelon KM, Hådell K, Jämsén PT, et al. (1998) The Plate Model: a visual method of teaching meal planning. DAIS Project Group. Diabetes Atherosclerosis Intervention Study. J Am Diet Assoc 98, 1155-1158.

17. Mithril C, Dragsted LO, Meyer C, et al. (2012) Dietary composition and nutrient content of the new Nordic diet. Public Health Nutr 16, $777-785$.

18. Sabinsky M, Toft U, Andersen KK, et al. (2012) Development of a meal index of dietary quality (Meal IQ) to assess the dietary quality of school lunches. Public Health Nutr 15, 2091-2099.

19. Thorsen AV \& Biltoft-Jensen A (2011) Udvikling af metode til måling af tallerkenspild og kokkenspild (Development of a Method to Measure Plate Waste And Kitchen Waste OPUS. An Internal OPUS Report). Søborg, Denmark: Division of Nutrition, National Food Institute, Technical University of Denmark.

20. Biltoft-Jensen A, Bysted A, Trolle E, et al. (2013) Evaluation of Web-based Dietary Assessment Software for Children: comparing reported fruit, juice and vegetable intakes with plasma carotenoid concentration and school lunch observations. Br J Nutr 110, 186-195.

21. Statistics Denmark (2014) StatBank Denmark: Income, consumption and prices. INDKF7 and INDKF11 2010. Copenhagen: Statistics Denmark. www.statistikbanken.dk (accessed February 2012).

22. Olsen MK and Schafer JL (2001) A two-part random-effects model for semicontinuous longitudinal data. J Am Stat Assoc 96, 730-745.

23. Laursen RP, Dalskov S-M, Damsgaard CT, et al. (2014) Back-transformation of treatment differences - an approximate method. Eur J Clin Nutr 86, 277-280.

24. Naturvårdsverket (2009) Mindskat svinn av livsmedel i skolkök cafeteria (Less Food Waste in the School Cafeteria). Stockholm, Sweden: Naturvårdsverket.
25. Baik J-Y \& Lee H (2009) Habitual plate-waste of 6- to 9-year olds may not be associated with lower nutritional needs or taste acuity, but undesirable dietary factors. Nutr Res 29, 831-838.

26. Bergman EA, Buergel NS, Englund TF, et al. (2003) Relationship of meal and recess schedules to plate waste in elementary schools. Oxford, MS: National Food Service Management Institute, The University of Mississippi. http://www.nfsmi.org/Information/ meal_recess_report.pdf (accessed September 2005).

27. Thorsen AV, Lassen A, Tetens I, et al. (2010) Long term sustainability of a worksite canteen intervention of serving more fruit and vegetables. Public Health Nutr 13, 1647-1652.

28. Story M, Kaphingst KM, Robinson-O’Brien R, et al. (2008) Creating healthy food and eating environments: policy and environmental approaches. Annu Rev Public Health 29, 253-272.

29. Swerissen H \& Crisp BR (2004) The sustainability of health promotion interventions for different levels of social organization. Health Promot Int 19, 123-130.

30. Andersen R, Biltoft-Jensen A, Christensen T, et al. (2014) Dietary effects of introducing school meals based on the New Nordic Diet - a randomized controlled trial in Danish children. $\mathrm{Br} \mathrm{J}$ Nutr 111, 1967-1976.

31. Holm L \& Kristensen ST (2012) Mad og måltider i skolen (Food and meals in school). In Mad, mennesker og maltider (Food, People and Meals), chapter 4, pp. 69-82 [JF Høyrup and MK Nielsen, editors]. Copenhagen, Denmark: Munksgaard Denmark.

32. Williamson DA, Han H, Johnson WD, et al. (2013) Modification of the school cafeteria environment can impact childhood nutrition. Results from the Wise Mind and LA Health studies. Appetite 61, $77-84$.

33. Sylow M (2013) Skolemadssatsningen I KBH, EAT 2007-2012 (School Meals Venture in Copenhagen, EAT 2007-2012). Copenhagen, Denmark: Københavns Madhus. 